Psychological Medicine, 1987, 17, 15-20

Printed in Great Britain

\title{
EDITORIAL
}

\section{Problems in the classification of personality disorder ${ }^{1}$}

The major clinical syndromes in psychiatry have shown themselves amenable to measurement and classification. Through the stimulus of coordination and collaboration involved in the preparation of the International Classification of Disease (ICD) (World Health Organisation, 1978) and the American Diagnostic and Statistical Manual of Mental Disorders (DSM-III) (American Psychiatric Association, 1980) we are now moving towards a common language and understanding of the main psychiatric syndromes. Disorders of personality, on the other hand, have proved much more resistant to satisfactory classification. For many years there has been an embarrassing failure to achieve common definitions that would be acceptable in both clinical and research practice. Some of these difficulties have been highlighted in recent years by the development of structured interview schedules for the assessment of personality. Although the problems may at times seem insuperable they need to be overcome before the label of 'personality disorder' can be stripped of its pejorative implications and given equivalent status with the major clinical syndromes in psychiatry.

\section{CRITERIA FOR DIAGNOSIS OF PERSONALITY DISORDER}

The twin gudgeons on which modern definitions of personality disorder pivot are the subjective distress suffered by the patient and the more easily measured social maladjustment resulting from the abnormal personality. Personality becomes disordered when these features are persistent and independent of other mental illness. This sounds straightforward enough but unfortunately the issue is still embroiled in controversy. As Jaspers (1963) has emphasized, 'variations of human nature that deviate from the average cannot be called sick as such and are not necessarily clinically abnormal'. The personality characteristics which allow measurement are not easily defined and, indeed, there is considerable argument as to whether such characteristics exist at all. There are several influential figures, of whom Mischel is perhaps the best known, who argue against the existence of any stable personality dimension because of poor correlation between behaviour or attitudes in one situation compared with another (Mischel, 1968, 1983).

Nonetheless, most observers would agree that the personality traits of some individuals are sufficiently maladaptive and abnormal as to constitute personality disorder. Such people have a tendency to behave habitually in a characteristic way even when such behaviour is socially inappropriate. When measuring these traits, both subjective distress and social malfunction need to be taken into account. There are arguments either for recording the trait and its social consequences conjointly or for doing so separately. In the DSM-III definition of personality disorder subjective distress alone can be the reason for a positive diagnosis. Thus it is not surprising that in two American structured interview schedules for assessing personality disorder (Loranger et al. 1983; Spitzer et al. 1985) the presence of a trait and the social impairment associated with its presence are recorded separately. In other schedules (Tyrer \& Alexander, 1979; Mann et al. 1981; Stangl et al. 1985) the assumption is made that when a personality trait is present to an abnormal degree, then pari passu it is also associated with social impairment.

The nature of the trait to be measured is also unclear. Personality cannot be recorded as easily as a psychiatric symptom, although objective behaviour can. As there is a whole range of possible behaviour patterns it is far from certain which should be recorded as indicative of personality disorder. Widiger \& Frances (1985) argue that no particular behaviour is specific for any disorder, but some 'prototypic' acts which characterize the disorder may be more specific than others. Among other things they argue for a system of classification which depends mainly on different weights being attached to defined abnormal behaviour. If disorder was only concerned with behaviour it would

\footnotetext{
1 Address for correspondence: Dr P. Tyrer, Mapperley Hospital, Porchester Road, Nottingham NG3 6AA.
} 
be easier to achieve acceptable criteria of measurement. Social, occupational and personal maladjustment includes both behaviour and distress (Platt, 1981; Remington \& Tyrer, 1979) so that a more comprehensive assessment of social functioning is also necessary.

An alternative approach is to determine the amount of social impairment and decide by appropriate parameters the extent to which the impairment is caused by personality features. This method also has problems in that cultural factors that are independent of personality can influence behaviour that would otherwise be regarded as maladaptive (Alarcon, 1983). In this context it is important to assess social functioning with reference to the personal background and life circumstances of the subject. The establishment of 'personality-created maladjustment' is an essential component of one interview schedule, the Personality Assessment Schedule (PAS) (Tyrer \& Alexander, 1979), in which the rating of personality abnormality is determined by its effect on social adjustment alone.

It has also been argued that a dimensional approach to the classification of personality disorder is more suitable than a categorical one (Presley \& Walton, 1973; Frances, 1982; Wigider \& Frances, 1985). The advocates of a dimensional approach imply that personality disorder differs from normal variation in personality only in terms of degree, and to some extent this is supported by empirical studies (Tyrer \& Alexander, 1979). However, there remains the possibility that some disorders are qualitatively distinct and may not be identified by means of a dimensional approach. Thus some borderline and schizotypal features (Khouri et al. 1980) could be interpreted as qualitatively different phenomena that are not found to any degree in other populations.

A separate group, termed personality accentuation, has also been proposed (Leonhard, 1968). This group can be thought of as intermediate between normal personality and personality disorder and is of interest because it may modify the nature and course of Axis I disorders. However, it would be wrong to assume that personality accentuation is on a continuum between normal personality and personality disorder because some personality abnormalities may never in themselves be sufficient to create the severity of disturbance necessary for the diagnosis of personality disorder. There is some evidence to suggest that there are relatively few severe personality disorders, perhaps only two or three, but that many more can be identified at a lower level of severity equivalent to that of personality accentuation (Ferguson et al. 1986). The dimensional approach is still not yet validated.

\section{WHO SHOULD BE INTERVIEWED?}

Robert Burns' famous words - 'O wad some Pow'r the giftie gie us, to see oursels as others see us' could be a charter for those who recommend that personality disorder should only be assessed by interviewing an informant. As this diagnosis is concerned with the attribution of socially undesirable characteristics there may be a tendency for many subjects to minimise abnormalities or attribute them to external factors. This could explain the finding in one study (Stangl et al. 1985) that only $29 \%$ of a group of inpatients administered the Structured Interview for DSM-III Personality Disorders (SIDP) without an informant received a personality disorder diagnosis, whereas $53 \%$ of patients with an informant had a personality disorder. On the other hand, Guze (1976) has shown that, contrary to popular view, most antisocial personalities are not untrustworthy historians.

It is reasonable to argue that whereas a normal variation in personality may be rated correctly by the subject the level of impaired social functioning is best determined by those closest to him. Thus some authorities use the information only in the assessment of abnormal personality (Mann et al. 1981). This can lead to difficulty, since not all patients have an appropriate informant. It may be that those with the most severe forms of personality disorder have such disturbed relationships that a suitable informant with a long duration of acquaintanceship with the subject is impossible to find. Most of the other schedules (e.g. Structured Clinical Interview for DSM-III (SCID), SIDP and Personality Disorder Examination (PDE)) use the subject as the main source of information, although it is often recommended that the information obtained is corroborated by another source. In the PAS both the subject and the informant may be interviewed and a final personality score 
determined by the combination of both results. This process undoubtedly has merit in those rare circumstances when subjects seek deliberately to mislead the interviewer. No matter which method is used, brevity and clarity should not be completely sacrificed for the sake of reliability.

\section{SEPARATION FROM AXIS I DISORDERS}

It is often difficult to separate problems due to a personality abnormality from those due to a chronic or recurrent mental illness. As personality traits are looked upon as enduring characteristics, episode disturbances have tended in recent years to be reclassified as Axis I disorders. For example, the category of explosive personality disorder in DSM-II has been removed from the DSM-III personality disorder section because by definition the explosive behaviour contrasts with the individual's usual behaviour (Lion, 1982). This decision may appear arbitrary, as inconsistency in behaviour can be just as much a feature of personality disorder as any other. If these requirements were applied universally, borderline personality disorder (which seems to include many who are diagnosed as explosive personality disorder according to the ICD) should not be included on Axis II unless the typically impulsive, unpredictable and erratic behaviour are persistent. Similarly, cyclothymic personality disorder, described so clearly by Schneider (1923) and Kretschmer (1918), has been part of all personality classifications until recently. However, with the development of effective treatments for bipolar affective disorders it has been suspected that most patients with cyclothymic personality disorder suffer from manic-depressive psychosis or at least formes frustes of this condition and are therefore classified on Axis I (Akiskal, 1977).

There is also considerable difficulty in rating personality disorder in the presence of chronic mental illness (Coppen \& Metcalfe, 1965; Liebowitz et al. 1979). All structured interviews assessing personality attempt to rate patients when they are not suffering from an Axis I disorder, but when such disorders are chronic it is difficult to ignore manifest personality during this time. For example, how should personality be assessed in a chronic schizophrenic illness which commences at the age of 20 ? It seems artificial to base the assessment on characteristic features of the pre-morbid personality from the age of 16-20 and ignore the next few decades. Too frequently research studies have dealt with this dilemma by removing subjects suffering from schizophrenia or manic-depressive disorder from scrutiny (Barasch et al. 1985; Stangl et al. 1985).

The flow of traffic from Axis II to Axis I has not been all one way. In DSM-III the diagnosis of schizophrenia, simple type, becomes schizotypal personality disorder because its validity as an Axis I disorder in the absence of definite psychotic symptoms has been questioned (Stone et al. 1968). The apparent inconsistency of moving schizophrenia spectrum disorder (schizotypal) to Axis II while simultaneously removing affective spectrum disorder (cyclothymic) to Axis I has been highlighted in a trenchant critique of DSM-III personality disorders (Frances, 1980).

\section{ARRIVING AT AN ACCEPTABLE CLASSIFICATION OF PERSONALITY DISORDER}

The classical approach to classification has been to convert the excellent descriptions of authorities such as Kretschmer (1918) and Schneider (1923) into a form that leads to reliable measurement. This lies behind the successful development of DSM-III in America. Groups of experienced clinicians and biometricians meet to decide on appropriate personality types and then decide on the criteria which identifies them adequately on the basis of previous studies. Although this approach has been very successful it has one major flaw. It implies that the clinical descriptions are automatically valid and inviolate and that their formalization into diagnostic criteria gives them a degree of permanence. Much of future research is then concerned with the measurement of these criteria rather than the more fundamental questions lying behind the whole concept of personality disorders. Although the authors of DSM-III have indicated clearly the provisional nature of its categories and the need for constant revision of our diagnostic concepts there is a danger that the present classification will adopt the status of an ex cathedra pronouncement which cannot be challenged. In this context it is of interest to note that although borderline personality disorder now has an established place in the 
Table 1. Differences in classification of personality disorder between DSM-III, ICD and empirically derived classification

\begin{tabular}{|c|c|c|c|}
\hline \multicolumn{2}{|c|}{ Empırical (PAS) } & \multirow{2}{*}{$\begin{array}{l}\text { ICD (and two } \\
\text { additional } \\
\text { categories in } \\
\text { SAP) }\end{array}$} & \multirow[b]{2}{*}{ DSM-III } \\
\hline Main group & Subgroup & & \\
\hline Sociopathic & $\begin{array}{l}\text { Explosive } \\
\text { Sensitive- } \\
\text { aggressive }\end{array}$ & $\begin{array}{l}\text { Explosive } \\
\text { Sociopathic }\end{array}$ & $\begin{array}{l}\text { Antisocial } \\
\text { Borderline }\end{array}$ \\
\hline $\begin{array}{l}\text { Passive- } \\
\text { dependent }\end{array}$ & $\begin{array}{l}\text { Histrionic } \\
\text { Asthenic }\end{array}$ & $\begin{array}{l}\text { Hysterical } \\
\text { Asthenic }\end{array}$ & $\begin{array}{l}\text { Histrionic } \\
\text { Narcissistic } \\
\text { Dependent }\end{array}$ \\
\hline $\begin{array}{l}\text { Anankastic } \\
\text { (obsessional) }\end{array}$ & $\begin{array}{l}\text { Anxious } \\
\text { Hypochondriacal } \\
\text { Dysthymic }\end{array}$ & $\begin{array}{l}\text { Anankastic } \\
\text { Anxious (SAP) } \\
\text { Self-conscious (SAP) } \\
\text { Affective }\end{array}$ & $\begin{array}{l}\text { Compulsive } \\
\text { (obsessional) } \\
\text { Passive-aggressive }\end{array}$ \\
\hline Schizoid & $\begin{array}{l}\text { Paranoid } \\
\text { Avoidant }\end{array}$ & $\begin{array}{l}\text { Paranoid } \\
\text { Schizoid }\end{array}$ & $\begin{array}{l}\text { Schizoid } \\
\text { Schizotypal }\end{array}$ \\
\hline
\end{tabular}

American literature and has stimulated a great deal of research, its validity as a separate personality disorder has yet to be established (Pope et al. 1983; Kroll et al. 1981; Kroll et al. 1982).

The alternative method of classification is to adopt an agnostic approach and ignore previously described personality types. Information can be recorded in a large number of subjects from different backgrounds and a subsequent classification derived from statistical procedures, notably cluster analysis. One such method employing 24 major personality characteristics classifies personality disorder into four main groups: sociopathic, passive-dependent, anankastic and schizoid and these can be further subdivided into nine more groups which are essentially subgroups of the main categories (Tyrer \& Alexander, 1979; Ferguson et al. 1986). The Standardized Assessment of Personality (Mann et al. 1981) is based on the ICD but includes two other categories, the selfconscious and the anxious personalities. It is interesting, despite these differences, how many similarities there are between the empirically derived classifications and both the ICD and the DSM-III (Table 1). There is generally good agreement between them for most of the individual personality disorders, but the categories of anxious, hypochondriacal, dysthymic, narcissistic and borderline personalities are discordant. It is of interest that the two personality types that have caused so much controversy in the American literature, schizotypal and borderline personality disorder, are not found in the European classification. The failure to identify these categories by empirical method needs further investigation.

There is also considerable doubt about the classification of personality disorder when more than one abnormality is found after formal enquiry. One can either employ a hierarchical system in which one personality type takes precedence, or an open system in which all personality types qualifying for abnormality are listed together. In DSM-III an open system is normally used, but some personality disorders are ignored (e.g. passive-aggressive) if other personality disorders are also present. In defining this area investigators are constantly aware that personality is unique and that any form of classification is bound to oversimplify.

\section{RELIABILITY}

The issues already discussed account for some of the failure to achieve satisfactory reliability in the rating of personality disorder. Before the advent of formal interview schedules the levels of inter-rater reliability were so poor that satisfactory diagnosis was impossible (Zubin, 1967; Presly \& Walton, 1973; Walton \& Presly, 1973). Even with the introduction of DSM-III and more effectively defined criteria for diagnosis, early reliability studies were disappointing (Spitzer et al. 1980; Mellsop et al. 
1982). Reliability with structured interview schedules is much better and weighted kappa values of 0.7-0.8 are common (Tyrer et al. 1979; Mann et al. 1981, Stangl et al. 1985). Nevertheless, these values are less than the agreement achieved between raters with Axis I diagnoses. It may be that the language of personality abnormality also gives rise to confusion. At different levels the abnormality can be defined in dynamic, descriptive or behavioural terms, as in the case of borderline personality (Tarnopolsky \& Berelowitz, 1984). Confusion invariably results when these terms are used interchangeably and sometimes such a diagnosis conveys more information about the uncertainty of the psychiatrist than it does about the condition of the patient (Knight, 1953). Good reliability does not indicate validity and steady improvement in the levels of agreement on diagnosis can be achieved using unsatisfactory criteria (Kreitman et al. 1961). For example, antisocial personality disorder in DSM-III tends to achieve better levels of inter-rater reliability than other personality disorders (Mellsop et al. 1982; Hare, 1983), but this may only be because all criminal acts, no matter how generated, are regarded as indicative of antisocial personality disorder.

One form of agreement that may help towards establishing validity of a particular personality disorder is temporal reliability. Personality characteristics tend to be long lasting and are often said to be 'ingrained' (World Health Organization, 1978). Temporal stability of the measurement helps to differentiate it from the more ephemeral Axis I disorders and set the abnormality more firmly in the personality sphere. One of the major criticisms of the DSM-III categorization is that there are very few studies on temporal reliability (Widiger \& Frances, 1985), with the possible exception of borderline personality disorder (Barasch et al. 1985; McGlashan, 1986). The value of recording temporal reliability is illustrated by Mann and his colleagues (1981), who found satisfactory levels of agreement on the presence of personality disorder between interviews conducted 12 months apart, with the exception of cyclothymic personality disorder. This finding strongly supports its inclusion among Axis I disorders. The major diagnostic categories of the PAS also show good temporal reliability (Tyrer et al. 1979; Tyrer et al. 1983a) although there is considerable room for improvement.

It is important to regard all the current labels attached to personality disorder as provisional only. Until these categories have shown good temporal as well as inter-rater reliability their status should remain suspect.

\section{FUTURE DEVELOPMENTS}

Elucidating the core of disturbance in personality disorder remains an elusive goal but we are considerably nearer to it than we were 20 years ago, when the subject was felt to require close investigation (Shepherd et al. 1968). More collaboration is needed between the various researchers in the field in order to achieve common standards of agreement and criteria of measurement. Good cross-national reliability can be achieved (Tyrer et al. 1984) but there are many cultural aspects that need to be taken into account before a common classification emerges. Detailed longitudinal studies are needed to examine the relationship between personality status and specific mental disorders and the exact relationship between personality and illness in the borderline spectrum (WHO/ADAMHA, 1983). Preliminary evidence suggests that personality status is often much more important than Axis I in determining the outcome of psychiatric disorder (Tyrer et al. 1983b) and, if so, should enhance the importance of assessing personality status early on in the course of psychiatric illness.

None of this can be achieved without better agreement on what constitutes personality disorder. Axis II is now a gawky adolescent; it is beginning to realise its potential but at times it is clumsy and maladroit and can look silly. Nonetheless it is maturing fast and before long should be able to hold its own among its more mature colleagues in the family of psychiatric nosology.

P. TYRER AND B. FERGUSON 


\section{REFERENCES}

Akiskal, H. S., Djenderedjian, A. H., Rosenthal, R. H. \& Khanı, M. K. (1977). Cylothymic disorder. Validating criteria for inclusion in the bipolar affective group. American Journal of Psychiatry 134, 1227-1233.

Alarcón, D. A. (1983). A Latin American perspective on DSM-III. American Journal of Psychiatry 140, 102-105.

American Psychiatric Association (1980) Diagnostic and Statistical Manual of Mental Disorders, 3rd edition. American Psychiatric Association: Washington, DC.

Barasch, A., Frances, A., Hurt, S., Clarkin, J. \& Cohen, S. (1985). Stability and distinctness of Borderline Personality Disorder. American Journal of Psychiatry 142, 1484-1486.

Coppen, A. \& Metcalfe, M. (1965). Effects of a depressive illness on MPI scores. British Journal of Psychiatry 111, 236-239.

Ferguson, B. G., Tyrer, P. \& Alexander, J. (1986). Classifying personality disorder. In Personality Disorder: Diagnosis, Management and Classification (ed. P. Tyrer), John Wright: Bristol (in press).

Frances, A. (1980). The DSM-III personality disorders: a commentary. American Journal of Psychiatry 137, 1050-1054.

Frances, A. (1982). Categoncal and dimensional systems of personality diagnosis: a comparison. Comprehensive Psychiatry 23, 516-527.

Guze, S. (1976). Criminality and Psychtatric Dusorders. Oxford University Press: London.

Hare, R. (1983). Diagnosis of antisocial personality disorder in two prison populations. American Journal of Psychiatry 140, 887-890.

Jaspers, K. (1963). General Psychopathology, 7th edn, trans. J. Hoenig and M. W. Hamilton, Manchester University Press: Manchester.

Khouri, P. J., Haier, R. J., Rieder, R. O. \& Rosenthal, D. (1980). A symptom schedule for the diagnosis of borderline schizophrenia: a first report. British Journal of Psychiatry 137, 140-147.

Knight, R. (1953). Borderline states. Bulletin of Menninger Clinic 17, $1-12$.

Kreitman, N., Sainsbury, P., Morrisey, J., Towers, J. \& Scrivener, J. (1961). The reliability of psychiatric assessment: an analysis. Journal of Mental Science 107, 887-908.

Kretschmer, E. (1918). Der Sensitive Bezeihungswahn. Springer: Berlin.

Kroll, J. Sines, L., Martin, K., Lari, S., Pyle, R. \& Zander, J. (1981). Borderline personality disorder: construct validity of the concept. Archives of General Psychiatry 38, 1021-1026.

Kroll, J., Carey, K., Sines, L. \& Roth, M. (1982). Are there borderlines in Britain - a cross validation of US findings. Archives of General Psychiatry 39, 60-63.

Leonhard, K. (1968). Akzentuierte Persönlichkeiten. Verlag Volk und Gesundheit: Berlin.

Liebowitz, M., Stallone, F. \& Dunner, D. (1979). Personality features of patients with primary affective disorder. Acta Psychiatrica Scandinavica 60, 214-224.

Lion, J. R. (1982). A comparison between DSM-III and DSM-II personality disorders . In Personality Disorders: Diagnosis and Management (ed. J. R. Lion), pp. 1-31. Williams and Wilkins: Baltimore.

Loranger, A. W., Oldham, J. M., Russakoff, L. M. \& Susman, V. (1983). Personality Disorder Examination: A Structured Interview For Making DSM-Ill Axis II Diagnoses (PDE). The New York Hospital/Cornell Medical Centre: White Plains, NY.

McGlashan, T. (1986). The Chestnut Lodge follow up study. III. Long-term outcome of borderline personalities. Archives of General Psychiatry 43, 20-30.

Mann, A. H., Jenkins, R., Cutting, J. C. \& Cowen, P. J. (1981). The development and use of a standardized assessment of abnormal personality. Psychological Medicine 11, 839-847.

Mellsop, G., Varghese, F., Joshua, S. \& Hicks, A. (1982). The reliability of axis II of DSM-III. American Journal of Psychiatry 139, 1360-1361.

Mischel, W. (1968). Personality and Assessment. John Wiley: New York

Mischel, W. (1983). Alterations on the pursuit of predictability and consistency of persons: stable data that yield unstable interpretatuons. Journal of Personality 51, 578-604.

Platt, S. (1981). Social adjustment as a criterion of treatment success: just what are we measuring? Psychiatry 44, 95-112.

Pope, H. G., Jonas, J., Hudson, J., Cohen, B. \& Gunderson, J. (1983). The validity of DSM-III borderline personality disorder: a phenomenologic family history, treatment response and long term follow up study. Archives of General Psychiatry 40, 23-30.

Presly, A. S. \& Walton, H. J. (1973). Dimensions of abnormal personality. Britush Journal of Psychiatry 122, 269-276.

Remington, M. \& Tyrer, P. (1979). The social functioning schedule - a brief semi-structured interview. Social Psychiarry 40, 151-157.

Schneider, K. (1923). Die Psychopathischen Persönlichkeiten. Springer: Berlin.

Shepherd, M., Brooke, E. M., Cooper, J. E. \& Lin, T. (1968). An experimental approach to psychiatric diagnosis. Acta Psychiatrica Scandinavica, Suppl. 201.

Spitzer, R., Williams, J. \& Skodol, A. (1980). DSM-III: The major achievements and an overview. American Journal of Psychiatry, 137, 151-164.

Spitzer, R., Williams, J. B. W. \& Gibbon, M. (1985). Structured Clinical Interview for DSM-III-R Personality Disorders. New York State Psychiatric Institute: New York.

Stangl, D., Pfohl, B., Zimmerman, M., Bowers, W. \& Corenthal, C. (1985). A structured interview for the DSM-III personality disorders: a preliminary report. Archives of General Psychiatry 42, 591-596.

Stone, A. A., Hopkins, R., Mahnke, M. W., Shapiro, D. W. \& Silverglate, H. A. (1968). Simple schizophrenı: syndrome or shibboleth. American Journal of Psychiatry 125, 305-312.

Tarnopolsky, A. \& Berelowitz, M. (1984) Borderline personality: diagnostic attitudes at the Maudsley Hospital. Brittsh Journal of Psychiatry 144, 364-369.

Tyrer, P. \& Alexander, J. (1979). Classification of personality disorder. British Journal of Psychiatry 135, 163-167.

Tyrer, P., Alexander, A. S., Cicchetti, D., Cohen, M.S. \& Remington, M. (1979). Reliability of a schedule for rating personality disorders. British Journal of Psychiatry 135, 168-174.

Tyrer, P., Strauss, J. \& Cicchetti, D. (1983a). Temporal reliability of personality in psychiatric patients. Psychological Medicine 13, 393-398.

Tyrer, P., Casey, P. \& Gall, J. (1983b). Relationship between neurosis and personality disorder. British Journal of Psychiatry 142, 404-408.

Tyrer, P., Cicchetti, D. V., Casey, P. R., Fitzpatrick, K., Oliver, R., Balter, A., Giller, E. \& Harkness, L. (1984). Cross-national reliability study of a schedule for assessing personality disorders. Journal of Nervous and Mental Disease 172, 718-721.

Walton, H. J. \& Presly, A. S. (1973). Use of a category system in the diagnosis of abnormal personality. British Journal of Psychiatry 122, 259-268.

World Health Organisation (1978). Mental Disorders: Glossary and Guide to the Classification in Accordance with the Ninth Revision of the International Classification of Diseases. World Health Organisa. tion: Geneva.

WHO/ADAMHA (1983). Diagnosis and classification of mental disorders and alcohol - and drug-related problems: a research agenda for the 1980s. Psychological Medicine 13, 907-921.

Widiger, T. A. \& Frances, A. (1985). The DSM-III personality disorders. Archives of General Psychiatry 42, 615-623.

Zubin, J. (1967). Classification of the behaviour disorders. Annual Review of Psychology 18, 373-401. 